\title{
Unusual sequelae of surgery in the superior oblique tendon sheath syndrome
}

\author{
S. M. HAWORTH
}

Nottingham

The superior oblique tendon sheath syndrome was first described by Brown (1950). The essential feature is a limitation of elevation in adduction caused by a short or inadequately mobile anterior segment of the superior oblique tendon and its sheath.

Treatment of the condition is indicated if an abnormal head posture is necessary in order to maintain an adequate field of binocular single vision; if a manifest deviation has developed, but evidence of potential binocular functions remains; or if, in the apparent absence of binocular potential, a cosmetic defect can be improved. Those patients able to maintain an adequate field of binocular vision with a cosmetically satisfactory head posture should be kept under observation.

The recognized treatment is first to demonstrate the limitation of elevation in adduction by the traction test under general anaesthesia; secondly to divide the superior oblique sheath and usually its tendon; and lastly to confirm by a second traction test that full passive movement has been obtained. After this procedure it is not uncommon to find that active elevation in adduction is still limited. Some surgeons prefer to combine division of the sheath only with resection of the ipsilateral inferior oblique (Nutt and Mein, r963).

The present case is described because division of the right superior oblique tendon and sheath was followed by bilateral inferior oblique overaction, requiring bilateral inferior oblique recession. The patient also developed signs of alternating sursumduction, first demonstrated after the superior oblique surgery.

\section{Case report}

A boy first presented at the age of 2 years with a history of right convergent squint since birth. Gestation, birth, and general health were normal, but his father is reputed to have a squint. The visual acuity was $6 / 9$ unaided in each eye using a picture chart, with no significant refractive error, clear media, and normal fundi. He had a face turn to the right and elevation of the chin, but neither was marked. Binocular single vision may have been present with the abnormal head posture, but his age made its confirmation impossible; on a subsequent visit he appeared to make fusional movements to overcome a base-out prism and apparently converged binocularly from a depressed position. In the primary position there was a variable right convergent or divergent squint with right hypotropia.

Examination of the ocular movements showed limitation of elevation of the right eye, most marked on laevo-elevation.

The deviation measured $+3^{\circ} \mathrm{L} / \mathrm{R} 20^{\Delta}$ fixing right, and $+2^{\circ} \mathrm{L} / \mathrm{R}{ }_{10} \Delta$ fixing left, using a synoptophore. Accurate prism cover test was impossible. 


\section{Operation}

It was decided to admit the child for surgery because there was at least some evidence of pre-existing binocular single vision, notably the abnormal head posture and the absence of amblyopia.

At the age of 2 years and 9 months he was examined under general anaesthesia. The traction test showed marked limitation of the right eye on laevo-elevation. The right superior oblique tendon and sheath were therefore divided at the medial border of the superior rectus resulting in free passive movement of the eye in all directions of gaze.

Examination of the ocular movements 6 days later already showed overaction of both inferior $\stackrel{\widehat{D}}{\alpha}$ obliques, with underaction of the right superior oblique and a V phenomenon. On cover test he initially appeared to have binocular single vision for near, breaking down to a slight right to alter- $\vec{\circ}$ nating convergent squint with right hypotropia; in the distance he showed a moderate left to alternating divergent squint with slight left hypertropia. He appeared to converge binocularly.

In the succeeding months the eyes became rather more convergent and alternating hypertropia developed instead of the previously constant left hypertropia or hyperphoria. Also at this time it o was first noticed that the vertical deviation increased under cover, giving the appearance of alter- $\perp$ nating sursumduction.

9 months after the first operation the situation was as follows:

vision Right $6 / 9+$; left $6 / 9$ using picture charts.

COVER TEST Slight right convergent squint with alternating hypertropia/sursumduction for $\frac{0}{0}$ distance and near.

OGULAR MOVEMENTS Marked overaction of both inferior obliques with a $\mathrm{V}$ phenomenon

(Fig. I, overleaf).

SYNOPTOPHORE $15^{\circ}$ elevation Fixing right $0^{\circ} \mathrm{L} / \mathrm{R}_{3} \Delta$ Fixing left $+\mathrm{I}^{\circ} \mathrm{R} / \mathrm{L} 6 \Delta$

$$
\begin{array}{cl}
\text { Straight ahead } & \text { Fixing right }+4^{\circ} \mathrm{L} / \mathrm{R}_{4} \Delta \text { Fixing left }+7^{\circ} \mathrm{R} / \mathrm{L} 6 \Delta \\
{ }_{1} 5^{\circ} \text { depression } & \text { Fixing right }+{ }_{1} 5^{\circ} \mathrm{L} / \mathrm{R}_{7}{ }^{\Delta} \text { Fixing left }+{ }_{1}^{\circ} 8^{\circ} \mathrm{R} / \mathrm{L} 8 \Delta
\end{array}
$$

Apparently normal fusion with a small range.

PRISM GOVER TEST $0.5 \mathrm{~m}$. I2 ${ }^{\triangle}$ prism base-out with alternating hypertropia.

\section{Second operation}

He was readmitted to hospital and both inferior obliques were recessed $6 \mathrm{~mm}$. In the immediateo postoperative period there was a slight to moderate right convergent squint with alternating hypertropia and a V phenomenon, but the ocular movements no longer showed any overaction of the inferior obliques (Fig. 2, overleaf). During the succeeding months, however, a constant right hypertropia developed.

\section{Result}

The present position 18 months later, the patient being now aged 5 years, is as follows:

VISION Right and left 6/5 using single letters.

HEAD POSTURE Variable, usually a slight tilt to the left. 

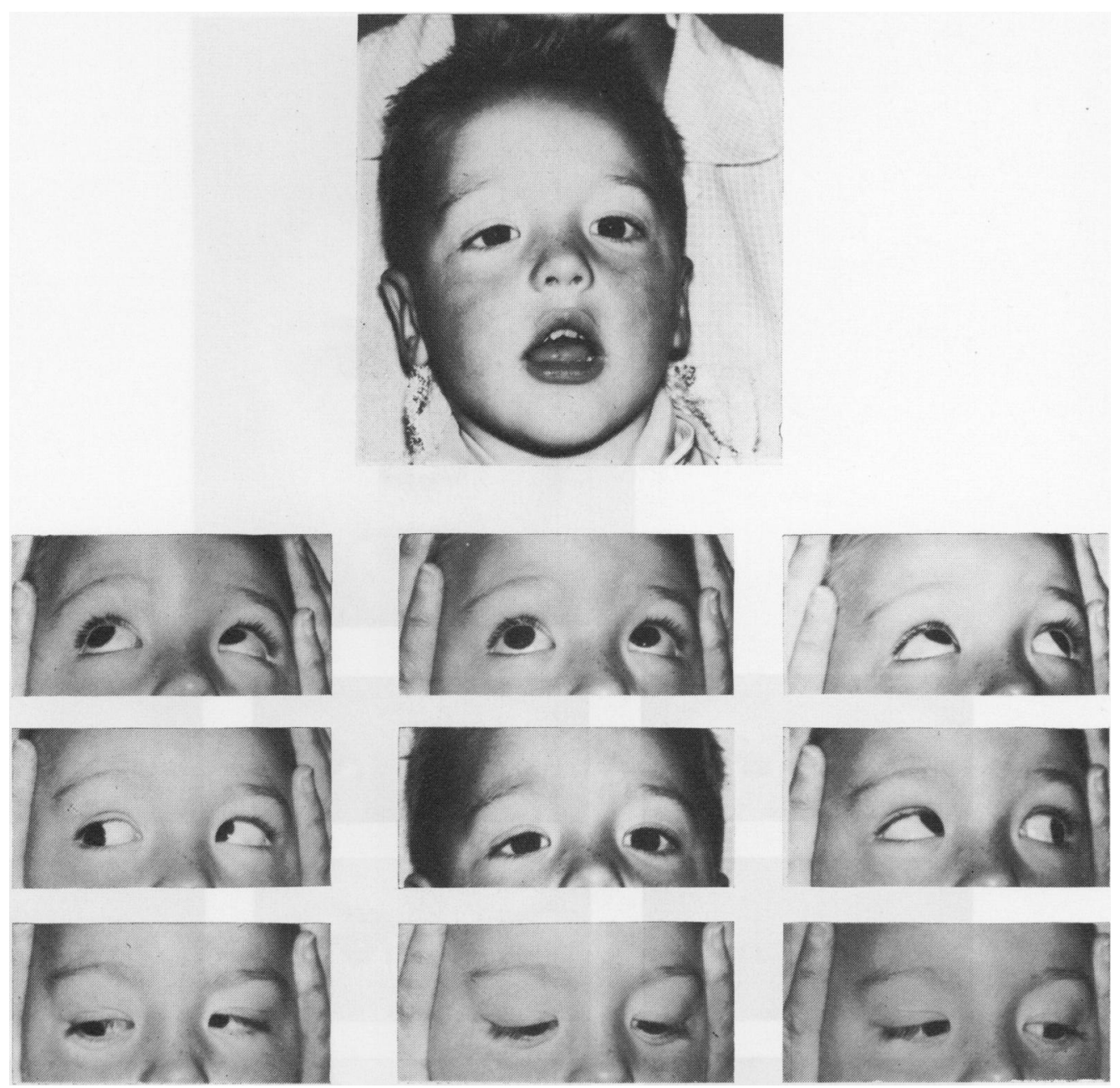

FIG. I. Appearance at age 3 years and 6 months (9 months after first operation)

GOVER TEST Slight right to alternating convergent squint with slight right hypertropia with or without abnormal head posture for distance and near.

On prolonged covering of the right eye the right hypertropia increases; on prolonged covering of the left the deviation reverses to a left hypertropia; this is very suggestive of alternating sursumduction.

OGULAR MOVEMENTS Nystagmoid movements occur on extreme version. There is slight underaction of the left eye on dextro-elevation and a $\mathrm{V}$ phenomenon.

The cosmetic appearance is very satisfactory and the head posture, although variable, is much less abnormal than before. The binocular status was always doubtful but he seems at present to have an abnormal correspondence with a small angle squint. For this reason, and because he readily suppresses either eye, it has not been possible to draw up a Hess chart.

Further treatment is not contemplated and the patient is being kept under observation until a more accurate assessment of his binocular vision can be made. 


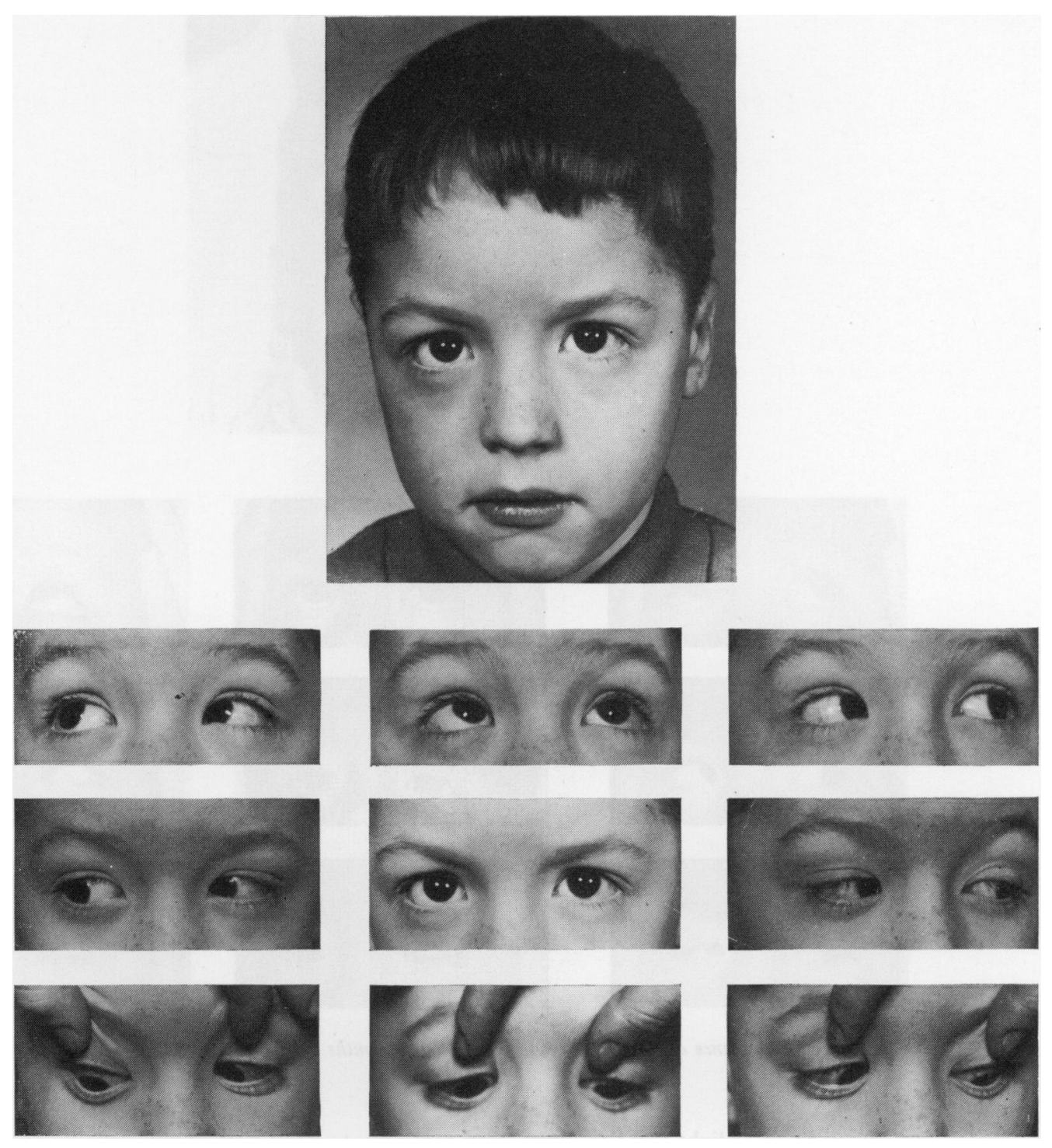

FIG. 2. Appearance at age 5 years (after second operation)

\section{Comment}

The case presented is unusual in two respects.

(x) Division of the superior oblique tendon sheath resulted in overaction of both inferior obliques. Usually such patients are undercorrected.

(2) Alternating sursumduction is present in this case apparently as a postoperative development. It is a difficult condition to diagnose in a young child since it requires fairly prolonged fixation and dissociation to unmask it. It is not uncommon in cases of congenital alternating convergent squint in which early surgery has been performed, but it is difficult to establish whether the condition is present from birth, which seems the 
more likely, or whether it is truly acquired after surgery. A similar problem is presented by the patient under review. However, Lowe (1969) mentioned the presence, at the ages of $5 \frac{1}{2}$ and 18 years, of alternating sursumduction in a girl showing spontaneous recovery from a bilateral superior oblique tendon sheath syndrome. This suggests that surgery is not the cause of the alternating sursumduction, but it may be a precipitating factor.

\section{Summary}

This report describes a case of the superior oblique tendon sheath syndrome in which division of the superior oblique tendon and sheath resulted in reversal of the vertical deviation with bilateral inferior oblique overaction and the appearance of alternating sursumduction. These sequelae are unusual.

I should like to thank Dr. Alan Stanworth and Miss Joyce Mein for their advice and encouragement in the production of this report and Miss Vanessa Clark for secretarial assistance.

\section{References}

BRown, A. w. (1950) In "Strabismus Ophthalmic Symposium", ed. J. H. Allen, p. 205. Mosby, St. Louis LOWE, R. F. (1969) Brit. 7. Ophthal., 53, 466 Nutr, A. B., and mein, J. (1963) Trans. ophthal. Soc. Aust., 23, 57 